\title{
Cloning of transgenic tobacco BY-2 cells; an efficient method to analyse and reduce high natural heterogeneity of transgene expression
}

\author{
Eva Nocarova and Lukas Fischer*
}

Address: Charles University in Prague, Faculty of Science, Department of Plant Physiology, Vinicna 5, CZ 12844 Prague 2, Czech Republic

Email: Eva Nocarova - evanocarova@seznam.cz; Lukas Fischer* - lukasf@natur.cuni.cz

* Corresponding author

Published: 22 April 2009

BMC Plant Biology 2009, 9:44 doi:1 0.1 I86/I 47/-2229-9-44

This article is available from: http://www.biomedcentral.com/I47/-2229/9/44

(C) 2009 Nocarova and Fischer; licensee BioMed Central Ltd.

This is an Open Access article distributed under the terms of the Creative Commons Attribution License (http://creativecommons.org/licenses/by/2.0), which permits unrestricted use, distribution, and reproduction in any medium, provided the original work is properly cited.

\begin{abstract}
Background: Phenotypic characterization of transgenic cell lines, frequently used in plant biology studies, is complicated because transgene expression in individual cells is often heterogeneous and unstable. To identify the sources and to reduce this heterogeneity, we transformed tobacco (Nicotiana tabacum L.) BY-2 cells with a gene encoding green fluorescent protein (GFP) using Agrobacterium tumefaciens, and then introduced a simple cloning procedure to generate cell lines derived from the individual transformed cells. Expression of the transgene was monitored by analysing GFP fluorescence in the cloned lines and also in lines obtained directly after transformation.
\end{abstract}

Results: The majority $(\sim 90 \%)$ of suspension culture lines derived from calli that were obtained directly from transformation consisted of cells with various levels of GFP fluorescence. In contrast, nearly $50 \%$ of lines generated by cloning cells from the primary heterogeneous suspensions consisted of cells with homogenous GFP fluorescence. The rest of the lines exhibited "permanent heterogeneity" that could not be resolved by cloning. The extent of fluorescence heterogeneity often varied, even among genetically identical clones derived from the primary transformed lines. In contrast, the offspring of subsequent cloning of the cloned lines was uniform, showing GFP fluorescence intensity and heterogeneity that corresponded to the original clone.

Conclusion: The results demonstrate that, besides genetic heterogeneity detected in some lines, the primary lines often contained a mixture of epigenetically different cells that could be separated by cloning. This indicates that a single integration event frequently results in various heritable expression patterns, which are probably accidental and become stabilized in the offspring of the primary transformed cells early after the integration event. Because heterogeneity in transgene expression has proven to be a serious problem, it is highly advisable to use transgenes tagged with a visual marker for BY-2 transformation. The cloning procedure can be used not only for efficient reduction of expression heterogeneity of such transgenes, but also as a useful tool for studies of transgene expression and other purposes. 


\section{Background}

Tobacco BY-2 cell line is the most popular and widely used cell line in plant research. Hundreds of scientific papers have been published using this line as a model to study various aspects of plant cell physiology. BY-2 cells are relatively homogenous, allowing studies of cell phenotypes [1]. Moreover, the cells exhibit high growth rate, enabling synchronization of cell divisions and cell-cycle analyses $[2,3]$. Being easily transformable either by particle bombardment [4] or by co-cultivation with Agrobacterium tumefaciens [5], transgenic derivatives of BY-2 cell line have had high impact in analyses of protein function by ectopic expression, gene knock-outs or translational gene fusions. GFP-tagging of proteins provides viable staining of different cell structures and organelles and analyses of subcellular protein localization $[6,7]$. The expression of fluorescent protein constructs can be easily monitored by fluorescence microscopy, whereas expression of non-tagged transgenes cannot be readily detected at individual cell level. In both cases, homogenous and stable expression of transgenes is highly desirable for both molecular/biochemical analyses of the total cell culture and for monitoring the effects of transgene expression in individual cells.

Variation in transgene expression in independent transgenic lines has been repeatedly reported to be related to the sequence of the introduced gene construct, involving RNA-sensing mechanism, the locus of insertion, the number of insertion copies, and the initial level of transgene expression [8-13].

The impact of the position of the inserted transgene in the chromosomal environment remains unclear, and the reports are partly controversial. In contrast to classical studies [8], Schubert with colleagues reported that the site of insertion had rather marginal effect; the expression of reporter genes under the control of a strong promoter was comparable among independent transgenic Arabidopsis plants harbouring the same transgene copy number [11]. However, silenced transgenes integrated into heterochromatin regions were not included in the study due to selection bias, as revealed by subsequent analyses of transgenic plants or cell lines generated without selection pressure $[12,14]$. Recently, Fischer with colleagues showed that the integration site significantly influences the sensitivity of the transgene to RNA silencing rather than affecting its initial expression level [15].

In contrast to numerous analyses of independent transgenic lines, much less attention has been paid to analyses of genetically identical clones $[16,17]$, which could bring valuable information about the variability of transgene expression independently of the positional effect.
Analyses of GFP-tagged transgenic BY-2 cell lines in our laboratory repeatedly produced only a low frequency of lines with well-balanced and stable fluorescence in all cells. In order to analyse the nature and sources of this variability, we transformed tobacco BY-2 cell line with a gene encoding free GFP, which allows simple in situ evaluation of transgene expression levels via assessment of green fluorescence. The homogeneity and stability of GFP fluorescence was monitored in both the primary calli obtained after Agrobacterium-mediated transformation and in suspension cultures derived from these calli. In order to eliminate high natural heterogeneity in GFP expression found in the primary lines, we introduced a simple cloning procedure. In addition to reducing the heterogeneity of GFP expression, the method also offered the opportunity to study the variability of transgene expression in genetically homogeneous clones, thus contributing to understanding of the impact of positional effect in transgene expression.

\section{Results \\ GFP fluorescence in primary calli and suspensions obtained after transformation}

About $70 \%$ of round-shaped calli that were obtained after the Agrobacterium-mediated transformation of BY-2 cells displayed GFP fluorescence intensity sufficient for reliable evaluation of its homogeneity. Out of these calli, the GFP fluorescence was homogenous over the whole callus in only $35-50 \%$ cases in three independent transformations (Figure 1a; Table 1). The rest of the calli contained regions with evidently different levels of GFP fluorescence. Out of these heterogeneous calli, $25 \%$ formed separate sectors (Figure 1a) and 36\% were mixed in a mosaic arrangement (Figure 1a; Table 1). The frequency of these categories was comparable in all three transformations.

Suspension cultures derived from the mixed calli contained cells with various GFP fluorescence intensities, as expected. However, also the majority ( $70 \%)$ of homogenous calli gave rise to heterogeneous suspensions (Figure $1 b)$. The cells with varied GFP fluorescence were predominantly in separate cell files, but occasionally were located even within a single cell file (Figure 1b). Classifying cells according to their GFP fluorescence intensities as high, low, or no fluorescence revealed that the proportions among the categories remained stable in the majority of the suspension cultures. Only in few lines $(6 / 3 ; 1 / 2)$ the proportion of cells with high GFP fluorescence gradually declined with time (Figure 2).

\section{Cloning of suspension cultures}

We introduced a simple and rapid method to generate clones from individual cells or cell files from the suspension cultures as follows: An excess of wild-type BY-2 suspension cells was added to the suspension culture of transformed (kanamycin resistant) cells in stationary 

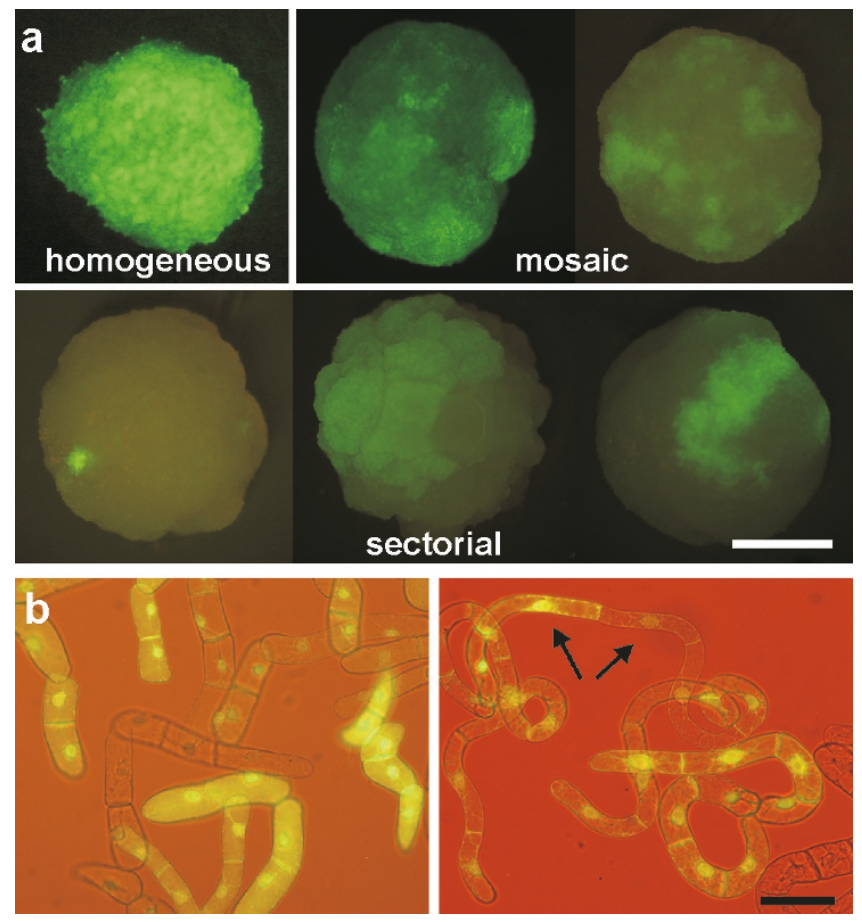

\section{Figure I}

Heterogeneity of GFP fluorescence in BY-2 calli and suspension cultures. (a) Primary calli obtained after transformation, showing calli with homogeneous and heterogeneous GFP expression either in mosaic or sectorial arrangements of cell populations with distinct GFP fluorescence. (b) Non-homogenous GFP expression in suspension cells. The arrows indicate cells with evidently different GFP expressions located in a single file. Scale bars: I mm for A, 50 $\mu \mathrm{m}$ for $\mathrm{B}$. phase of growth (Figure 3a). The mixture was then applied onto a Petri dish with solid MS medium containing kanamycin. Within 10 days, macroscopically visible calli appeared from individual resistant cells or cell files on the "feeder layer" of the wild-type BY-2 cells (Figure 3b, c). Few days later these "secondary" calli reached the size of 1 - $3 \mathrm{~mm}$ and could be transferred to a fresh medium for subsequent evaluation of GFP fluorescence homogeneity.

\section{GFP fluorescence in secondary calli and suspensions}

Cloning of suspension cultures with heterogeneous GFP fluorescence resulted in secondary calli, of which an average $93 \%$ gave rise to cell lines with almost exclusively homogenous GFP fluorescence (Table 1). Although the majority of secondary calli seemed to be homogenous, more than half of the suspension cultures derived from these calli still consisted of cell populations with various GFP levels (Table 1). The frequency of homogenous suspensions varied depending on the original suspension (Figure 4). Some lines (e.g. 1/3, 5/6) gave rise to both homogenous and heterogeneous suspension, whereas in the case of line $1 / 7$ practically all the secondary and tertiary suspensions were homogenous, with either high or low GFP fluorescence intensities. In the case of line $6 / 3$ or a secondary clone $5 / 6 a$, the original heterogeneity of GFP fluorescence persisted in all derived clones (Figure 4); even tertiary cloning of these "permanently heterogeneous" lines (e.g. 5/6am) did not diminish their heterogeneity. Generally, subsequent cloning of secondary clones produced almost exclusively homogeneous offspring. Their heterogeneity patterns in terms of proportions of individual GFP fluorescence categories corresponded to those of the original clones (Figure 4). Cloning of suspensions with homogeneous GFP fluorescence consistently gave homogenous subclones (e.g. 1/7d in Figure 4).

Table I: Frequencies of BY-2 calli and suspensions with homogeneous and heterogeneous GFP fluorescence

\begin{tabular}{ccccccc}
\hline & & \multicolumn{2}{c}{ Primary suspensions } & & \multicolumn{2}{c}{ Secondary suspensions } \\
\cline { 3 - 4 } GFP fluorescence in callus & Primary calli & Homogeneous & Heterogeneous & \multirow{2}{*}{ Secondary calli } & Homogeneous & Heterogeneous \\
\hline Homogeneous & $39.3 \% \pm 9.7 \%$ & $29.2 \% \pm 5.3 \%$ & $70.8 \% \pm 5.3 \%$ & $93 \% \pm 2.3 \%$ & $46.3 \% \pm 5.4 \%$ & $53.7 \% \pm 5.4 \%$ \\
\hline Heterogeneous - mosaic & $35.8 \% \pm 13 \%$ & $0 \%$ & $100 \%$ & $7 \% \pm 2.3 \%$ & $0 \%$ & $0 \%$ \\
\hline Heterogeneous - sectorial & $24.9 \% \pm 6.8 \%$ & $0 \%$ & $100 \%$ & $0 \%$ & $100 \%$ \\
\hline
\end{tabular}

Frequencies of homogeneous and heterogeneous calli and suspension cultures derived from these calli in primary lines obtained after transformation, and in secondary lines produced by cloning of primary heterogeneous (!) suspensions. Values represent means \pm SD ( $\mathrm{n}=3$ ); data are from three independent transformations; in every replication the number of evaluated lines was $60-80$ for calli and $\sim 20$ for suspensions). 

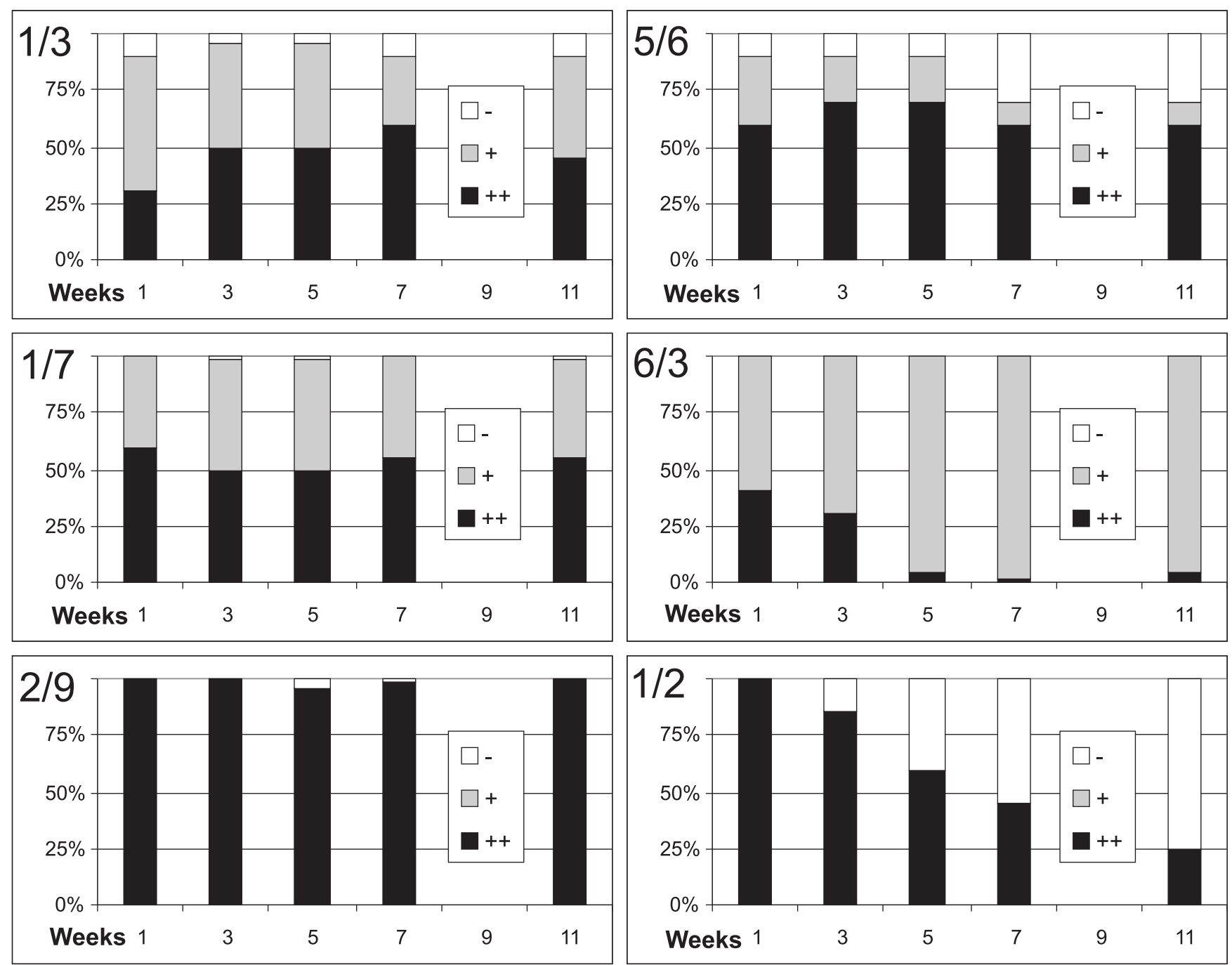

Figure 2

Changes in frequency of GFP-expression categories in selected primary BY-2 suspension cultures with time. GFP-expression categories: ++, strong fluorescence; + weak fluorescence, - no fluorescence.

The proportions of GFP fluorescence categories in both hetero- and homogeneous suspensions remained stable for months in almost all cloned secondary suspensions (data not shown).

\section{Molecular analysis of the causes of GFP fluorescence heterogeneity}

Analysis of T-DNA insertions in individual clones by Southern hybridisation (Figure 5) revealed that GFP fluorescence heterogeneity could have several causes. Lines $1 /$ 7 and $1 / 3$ were composed of two genetically different clones that were separable by cloning, as shown by comparing $1 / 7 \mathrm{~d}$ with $1 / 7 \mathrm{o}$ or $1 / 3 \mathrm{f}$ with other $1 / 3$ clones (Figure 5). Other clones that also strongly differed in their proportions of the GFP fluorescence categories (Figure 4) seemed to be genetically identical, as shown by comparing $1 / 3 a, 1 / 3 c$ and $1 / 3 d$ or $5 / 6 a, 5 / 6 b, 5 / 6 h$ and $5 / 6$ j samples, where the GFP probe hybridised with equally-sized restriction fragments after cleavage with HindIII or BamHI (Figure 5a). A possible presence of mutations within the $35 S$ promoter or GFP sequence was excluded by sequencing of 35S-GFP cassettes obtained by PCR amplification; all sequences obtained from individual $5 / 6$ clones $5 / 6 a$, $5 / 6 \mathrm{~b}, 5 / 6 \mathrm{~h}$ and $5 / 6 \mathrm{j}$ were identical (data not shown).

Genetically identical clones of lines $1 / 3$ and 5/6 were further analysed with respect to DNA methylation. The 35SGFP cassette was cleaved out with EcoRI and HindIII, and exposed to the action of several methylation-sensitive enzymes (Bsu15I, Eco72I and Eco47I). Subsequent South- 

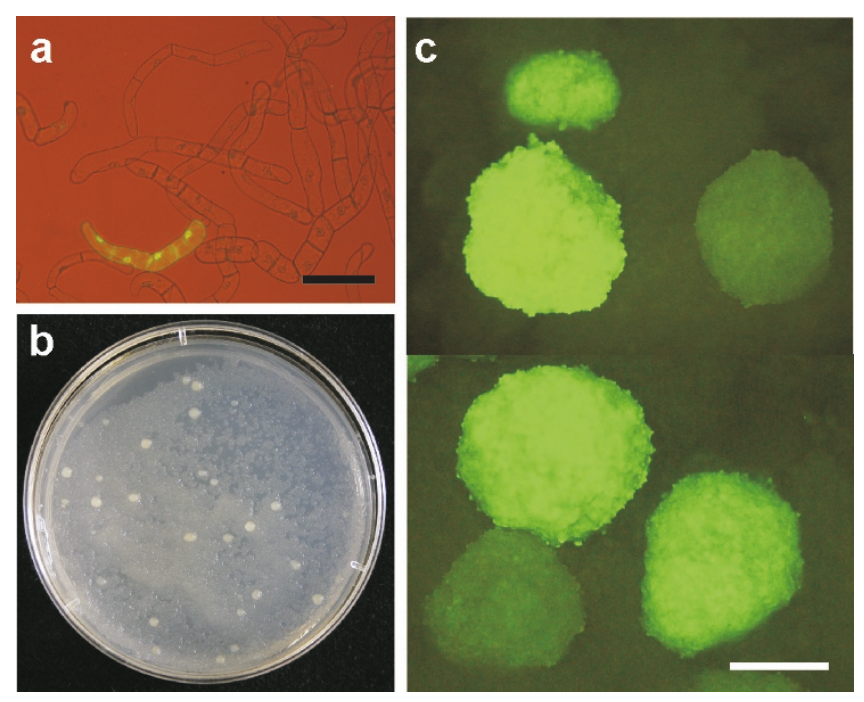

Figure 3

A scheme of the BY-2 cloning procedure. (a) Mixture of transgenic and wild-type lines before plating onto solid media. (b) Cloned calli emerging on the feeder layer $\sim 10$ days after plating. (c) Cloned calli of a heterogeneous line observed with a fluorescence stereomicroscope. Scale bars: $\mathrm{I} 00 \mu \mathrm{m}$ for $\mathrm{A}$, I $\mathrm{mm}$ for $\mathrm{C}$.

ern blot analysis did not reveal any change in cytosine methylation at the analysed restriction sites, with the exception of the completely silenced clone $5 / 6 \mathrm{j}$, whose DNA seemed to be methylated in the Bsu15I and Eco72I restriction sites (Figure 5b).

\section{Discussion \\ Monitoring of GFP fluorescence - a suitable way to estimate GFP expression in situ}

The green fluorescent protein (GFP) is an important reporter molecule for monitoring gene expression and protein localization in vivo, in situ, and in real-time observation. GFP fluorescence is stable, species-independent, and can be followed non-invasively in living cells where the green fluorescence reports active transcription and translation of the GFP gene [18]. Because of its simplicity, monitoring GFP fluorescence has been also routinely used in transgene silencing studies $[19,20]$. Although GFP is generally very stable [21], some differences in protein or fluorescence levels may occur due to protein degradation under certain treatments or in certain cell types. Nevertheless, in phenotypically homogeneous cell lines cultured under stable conditions, monitoring GFP fluorescence can be regarded as a suitable method for reliable estimation of GFP expression levels.

\section{Sources of GFP expression heterogeneity}

Analysis of GFP fluorescence in primary suspensions obtained either directly from transformation or from secondary and tertiary clones revealed the coexistence of cell populations with different T-DNA insertions in some primary lines, representing genetic heterogeneity. Although, the majority of GFP-expression heterogeneity is most likely determined epigenetically.

\section{Genetic heterogeneity}

Southern hybridisation of genomic DNA isolated from selected clones of lines $1 / 7$ and $1 / 3$ clearly documented that even the round-shaped primary calli can contain cell populations with different T-DNA insertions. Because the probability of plating independently transformed cell files so closely together was low when considering plating density of 30 - 50 calli per $6 \mathrm{~cm}$-diameter plate, these cells are likely to represent the offspring of independently transformed cells that were located in a single cell file. Considering the large number of plated cells and transformation efficiency of $\sim 0.1-0.5 \%$, the results indicate that there could be cell files that are highly susceptible to Agrobacterium-mediated transformation. Alternatively, the genetically mixed calli could represent the offspring of a single cell transformed in S or G2 phase of the cell cycle with multiple T-DNAs, which then segregated unequally to daughter cells during mitosis.

\section{Epigenetic heterogeneity}

Analyses of genetically identical lines have documented developmentally- and environmentally-derived variability in transgene expression [10,17] and in stress-induced silencing [16]. In our study, GFP expression also varied among genetically identical clones even though the cells were phenotypically homogeneous and were cultured under stable conditions. This indicates that factors other than environmental or developmental or stress situations can induce changes in GFP expression. Gene expression is generally influenced by specific chromatin marks that may be present on both DNA and associated proteins [22]. Our methylation analysis of the GFP gene from selected genetically identical lines revealed that cytosins in analysed restriction sites were methylated only in some restriction sites and only in the line 5/6j with completely silenced GFP expression. This indicates that all other observed differences in GFP expression levels and heterogeneity are either independent of DNA methylation or methylation occurred in locations other than the selected restriction sites. The epigenetic state of chromatin is heritable through cell division, but can be easily modulated in response to certain triggers. For example, changes at the chromatin level such as cytosine methylation can accompany gene or transgene silencing [22] although the presence of methylated DNA is not necessarily related to the silenced phenotype [23]. 
a
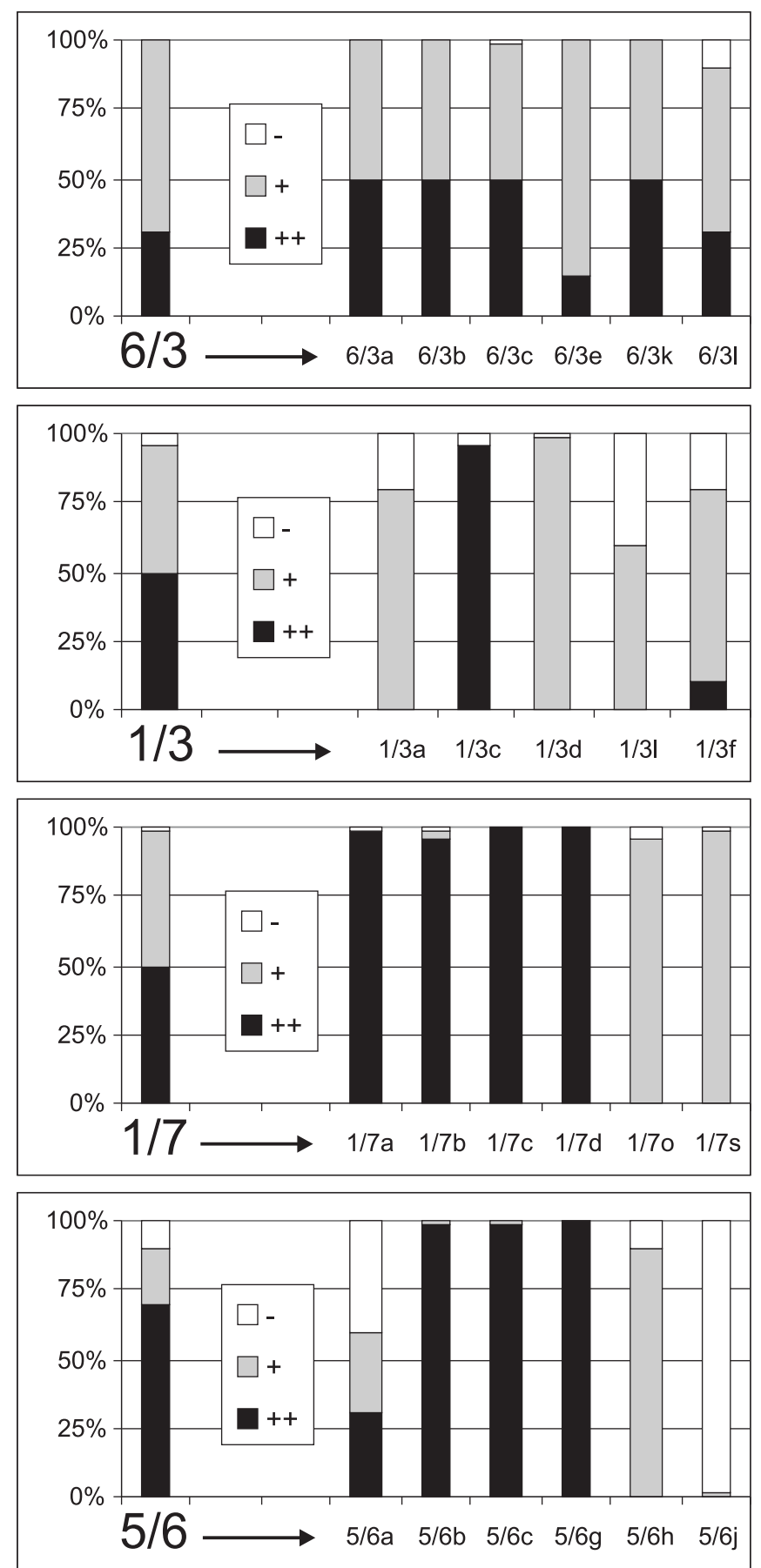

b
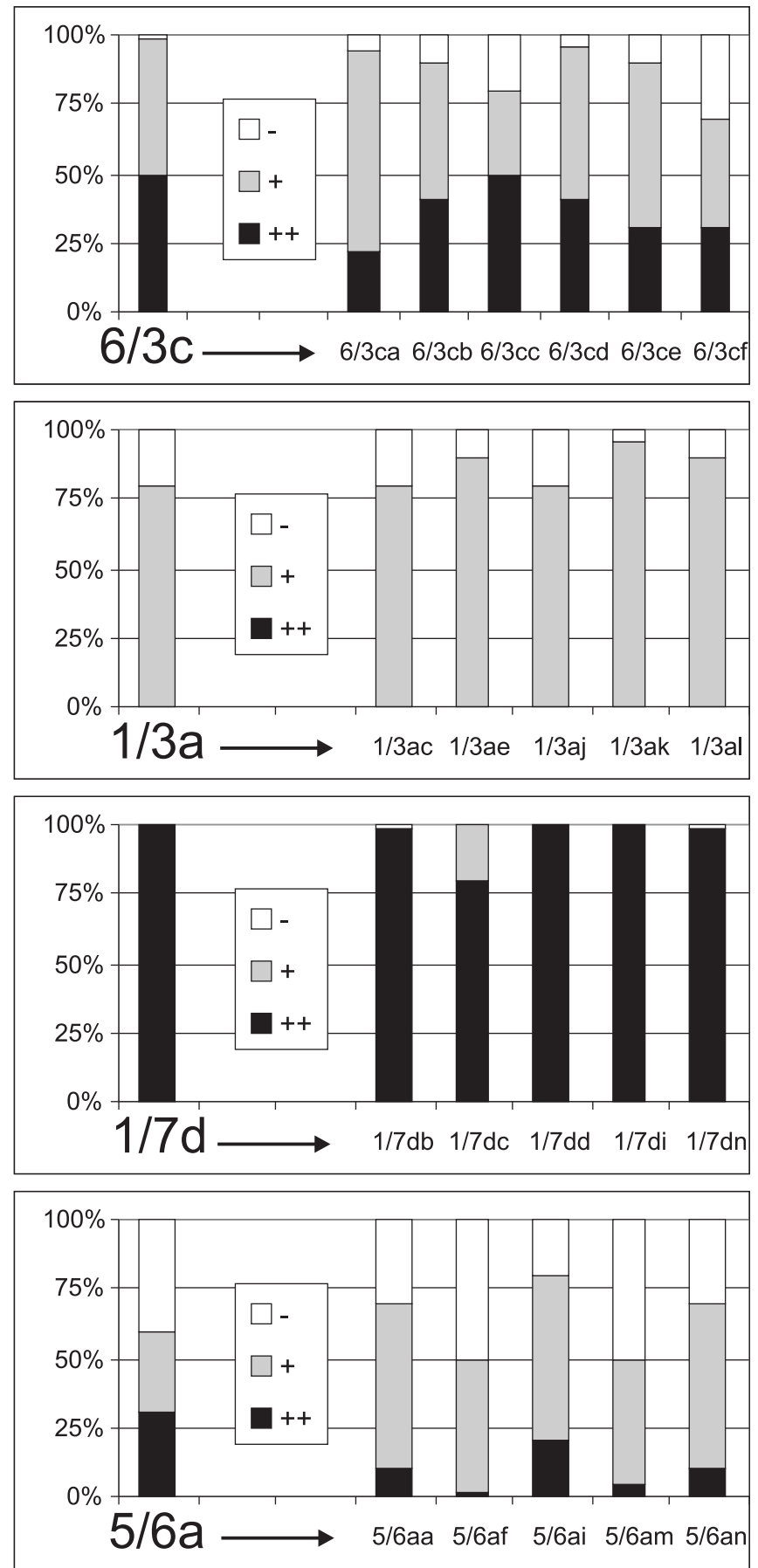

Figure 4

Frequency of GFP-expression categories after the cloning of primary and secondary BY-2 lines. (a) Primary cloning of suspensions obtained from calli directly after transformation. (b) Secondary cloning of selected subclones. The cloned lines are on the left, with progenies indicated by letters on the right. GFP-expression categories: ++, strong fluorescence; + weak fluorescence, - no fluorescence. 

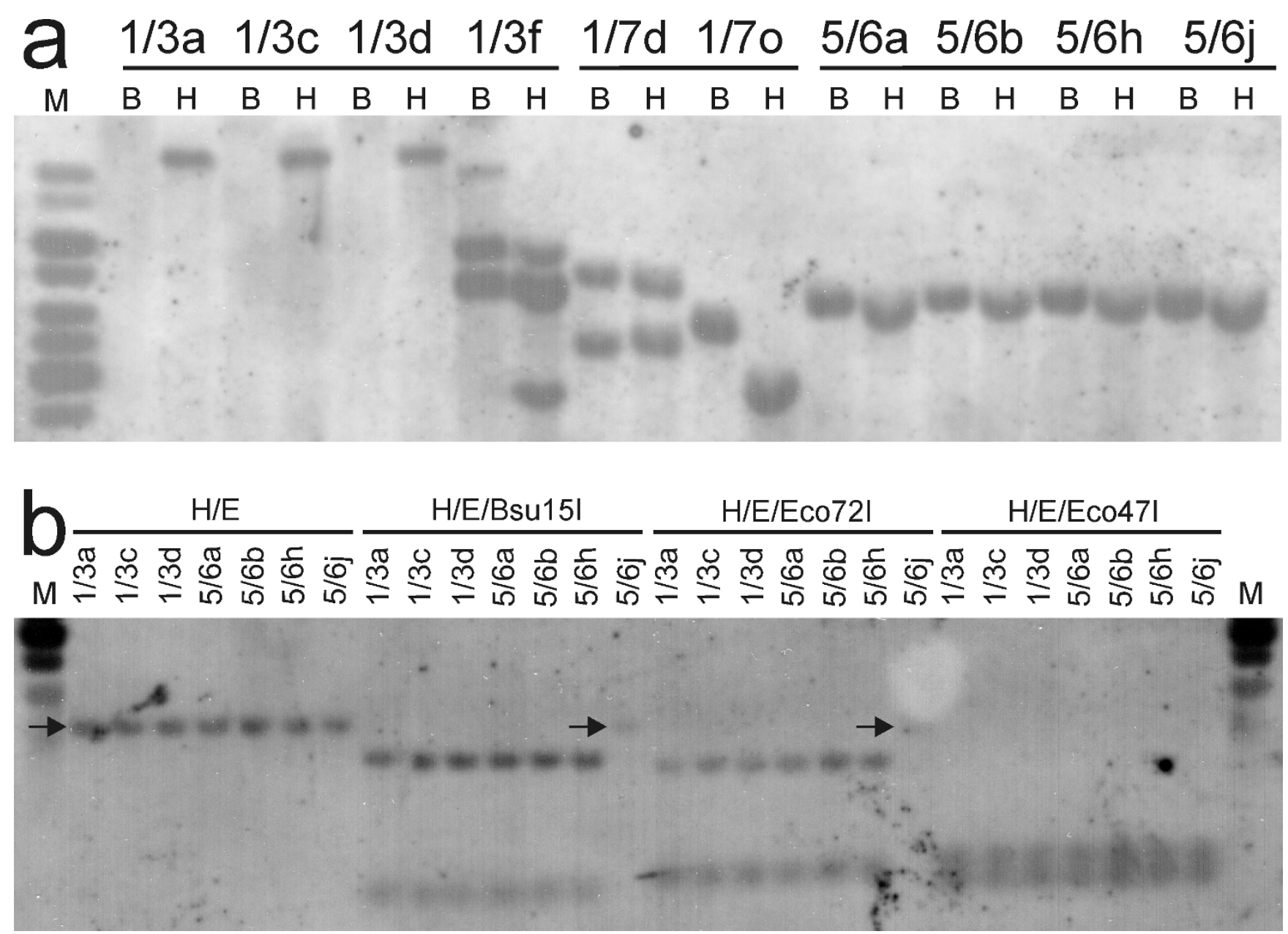

\section{Figure 5}

Molecular analysis of selected primary clones. (a) analysis of T-DNA insertions by Southern hybridization of total genomic DNA digested with either BamHI (B) or HindIII $(\mathrm{H})$. (b) Methylation analysis by Southern hybridization of total genomic DNA digested with HindIII $(\mathrm{H})$ and EcoRI $(\mathrm{E})$, cleaving out the 35S-GFP cassette, and further with methylation-sensitive endocucleases Bsu I5I, Eco72I or Eco47I, having restriction sites within the cassette; arrows indicate position of uncleaved 35SGFP cassette. The blots were hybridised with DIG-dUTP-labelled GFP probe. M, molecular weight ladder.

Positional effect in the chromosomal environment at the site of transgene integration is known to influence transgene expression [13], although it seems to have much lower impact [11] than previously assumed [8]. Different sites, or arrangements, of T-DNA insertion can influence the accessibility/susceptibility of transgene to epigenetic regulation at either transcriptional or posttranscriptional level $[15,24]$; reviewed in [13]. Specifically in case of integration into heterochromatin region, the epigenetic information is almost regularly reflected in the chromatin structure of the inserted T-DNA, which results in transgene silencing $[12,14,25]$. In our experiments, GFP expression often varied strongly among clones with identical T-DNA insertions. For example, a single insertion resulted in completely different transgene expression patterns in genetically identical subclones of line $5 / 6$ (Figure
4). In previous studies, transgene expression was analysed in clonal plant replicates generated long time after the integration event $[10,17]$. In contrast, the use of cell cultures and their cloning allowed us to analyse clones/replicates that arose immediately after the transgene integration. Since our results showed that GFP-expression patterns were stable and heritable in the cloned lines, the various expression patterns observed among genetically identical clones had to be established and stabilized in the offspring of the primary transformed cells early after the integration event. The process of integration of "naked" TDNA is known to be accompanied by de novo establishment of specific chromatin composition and structure [25]. Our results clearly document that in certain insertion sites the establishment of different epigenetic states/trans- 
gene-expression patterns is accidental and independent of chromosomal environment in BY-2 cells.

Heterogeneity in GFP expression derived from the coexistence of either genetically or epigenetically different cells within the primary lines was in some cases resolved by cloning. However, in many clones (e.g. line 6/3; Figure 4) the heterogeneity in GFP expression among individual cells persisted and could not be resolved by subsequent cloning, representing a state of "permanent expression heterogeneity". Van Leeuwen with colleagues also observed spatial and temporal variability in the expression of luciferase gene in different leaves and leaf sectors of stably transformed Petunia plants [10]. The authors attributed this mosaic character of transgene expression to temporal changes in the accessibility of promoter sequences for transcription factors, or variable levels of these factors in different leaf sectors at a time [10]. The pattern of this transgene expression variability was more or less specific for individual lines [10], similarly to the heterogeneity patterns observed in our lines $6 / 3 c, 1 / 3 a, 5 /$ $6 \mathrm{a}$ and their subclones (Figure 4 ). Since the heterogeneity patterns were heritable through subsequent cloning, they could be the result of specific variation in epigenetic states at a certain genomic locus [26].

Finally, the remaining evident cause of heterogeneity or instability of GFP expression is silencing [27]. Occurrence of transgene silencing was indicated by the presence of cells with contrasting GFP levels in a single cell file (Figure 1b) and by a gradual decline in the frequency of GFPexpressing cells observed in some lines (e.g. line 1/2; Figure 2). Silencing at the transcriptional level in connection with DNA methylation was demonstrated by the detection of methylated cytosin in clone 5/6j (Figure 5b). The role of methylation was confirmed by using the DNAdemethylation drug, 5-azacytidin [28], which reactivated GFP expression in several lines after several months of silenced GFP expression (e.g. lines 1/2, 5/6j; Nocarova and Fischer, unpublished). Silencing of transgene expression is naturally triggered mainly by high transcript levels [11], but may also be related to changes in the epigenetic status of plant genomic DNA in the process of dedifferentiation [29] that accompanies preparation of transgenic plants and plant cell lines.

\section{Cloning of plant cells - history and future}

The first reports of cloning non-transgenic plant cells were published long time ago [30,31]. The method of cloning transgenic plant cell line introduced in our study has not been, to our knowledge, published and used before. Müller with colleagues described protoplast-based cloning of transgenic wheat lines, although this method was time-consuming and induced high frequency (up to 50\% of clonal cells lines) of transgene silencing [16]. It indi- cates that the process of protoplast formation and regeneration may be accompanied by stress-induced epigenetic changes, causing transgene silencing [16]. The minimal occurrence of silencing in our experiments indicates that the drug selection of resistant cells during the cloning procedure causes significantly little stress. In contrast to protoplast-based cloning, our method does not always produce clones from single cells, because BY-2 cells remain temporarily attached in files. However, as the files originate from single cells, they are genetically homogeneous and calli derived from these files represent real clones. Although our cloning procedure did not, against expectations, lead exclusively to lines with homogenous GFP expression, clearly the cloning method is an effective way to substantially increase the number of homogenous lines. Whereas only $\sim 10 \%$ of the primary cell lines were homogenous just after transformation, the cloning of largely heterogeneous lines produced additional $43 \%$ of homogeneous cell lines (Table 1).

In addition to generating homogeneously expressing transgenic lines, the cloning procedure appears to be a suitable tool for detailed analysis of the induction and stabilization of epigenetic changes connected with T-DNA insertion into the plant genomic DNA. Thus, in a modified arrangement, cloning of lines with silenced GFP expression using 5-azacytidin-containing media produced clones with reactivated GFP expression (Nocarova and Fischer, unpublished). Another possible use of the cloning procedure includes the cloning of epigenetically shifted lines habituated to certain conditions [32]. In transgenic lines carrying a negative selection gene whose expression is lethal under certain treatment, mixing an abundance of such a line with non-transformed line would enable cloning of reversed, non-transformed lines.

\section{Conclusion}

By analysing GFP fluorescence in tobacco BY-2 cells, we found that expression of GFP transgene was highly heterogeneous in the majority of transgenic lines obtained directly from transformation. This heterogeneity had two causes: (1) genetic heterogeneity, namely the presence of cells with different T-DNA insertions; and (2) epigenetic heterogeneity, including transgene silencing, formation of stable epigenetic states early after transformation, and "permanent heterogeneity" with fluctuating changes in GFP expression. The genetic heterogeneity and the presence of cells in different but stable epigenetic states was responsible for almost half (43\%) of the heterogeneity in the primary lines, and could be resolved by cloning. Because the cloning procedure can significantly increase the frequency/yield of homogenous lines, it is of high general impact for both molecular and biochemical analyses of BY-2 transgenic lines. In order to facilitate a simple way for assessment of transgene expression heterogeneity in 
both primary and cloned lines, it is highly advisable to use GFP-tagged transgenes. Alternatively, for transgenes that lack a visible, cell-autonomous phenotype the cloning procedure can be used to obtain genetically homogeneous lines with statistically higher chance of homogeneous transgene expression. Analysis of GFP expression in primary cell lines and their clones also showed that a single T-DNA insertion often resulted in various heritable transgene expression patterns/epigenetic states. These lines were probably established accidentally and became stabilized in the offspring of the primary transformed cells early after the integration event. Thus, the cloning procedure introduced in this study also appears to be suitable for analysing the sources of variability in transgene expression.

\section{Methods \\ Cultivation and transformation of BY-2 cell line}

Tobacco cell line BY-2 (Nicotiana tabacum L. cv. Bright Yellow 2 [33]) was cultured in modified MS medium [34]. Cells in suspension were subcultured every seventh day (1 $\mathrm{ml}$ of cells into $30 \mathrm{ml}$ of liquid media). Stock BY-2 calli were maintained on media solidified with $0.7 \%(\mathrm{w} / \mathrm{v})$ agar and subcultured monthly. The cultures were kept in darkness at $26^{\circ} \mathrm{C}$; suspensions were placed on orbital incubator (IKA KS501, IKA Labortechnik, Staufen, Germany; orbital diameter $30 \mathrm{~mm}$ ). Suspensions were prepared by resuspending of $\sim 1 \mathrm{ml}$ of fresh calli in $30 \mathrm{ml}$ of liquid media by repeated pipetting through a cut tip (internal diameter $\sim 5 \mathrm{~mm}$ ).

Transformation of BY-2 line was performed by a slightly modified protocol introduced by [5]. A $2 \mathrm{ml}$ aliquot of 3day old BY-2 cells was co-cultivated with $200 \mu \mathrm{l}$ of an overnight culture of Agrobacterium tumefaciens strain C58C1 carrying a helper plasmid pGV2260 [35] and a modified binary vector $p C P 60$ [36] (kindly provided by dr. P. Ratet). The T-DNA contained a gene encoding redshifted green fluorescent protein [37] (kindly provided by ABRC) inserted under the control of CaMV 35 S promoter with a single enhancer region. The T-DNA further contained neomycin phosphotransferase gene (NPTII) driven by nopalin synthase promoter ( $p N O S$ ), which provided kanamycin resistance. After co-cultivation, the cells were washed with $60 \mathrm{ml}$ of $3 \%$ sucrose and $20 \mathrm{ml}$ of liquid medium containing $100 \mu \mathrm{g} / \mathrm{ml}$ cefotaxim (CEFTAX, Hikma Farmaceutica, Terrugem, Portugal) in Nalgene filter holder (Nalgene, Rochester NY, USA). Thereafter, the cells were plated onto solid medium containing $50 \mu \mathrm{g} / \mathrm{ml}$ kanamycin and $100 \mu \mathrm{g} / \mathrm{ml}$ cefotaxim. Kanamycin-resistant colonies appeared after 3 to 4 weeks in darkness at $26^{\circ} \mathrm{C}$. Transformed calli and suspensions were kept on media supplemented with kanamycin $(50 \mu \mathrm{g} / \mathrm{ml})$ for about two months and thereafter they were cultured as described for the BY-2 stock line.

\section{Assessment of GFP expression/fluorescence}

Round-shaped primary calli in size of $1-3 \mathrm{~mm}$ (4 weeks after the transformation) were transferred onto fresh media. After additional 2 weeks of cultivation, the homogeneity of GFP expression was evaluated as a green fluorescence using a fluorescence stereomicroscope (Leica MZ16F). Calli containing a few sectors of different GFP fluorescence intensities separated by sharp borders were classified as mixed calli with a "sector arrangement". If the regions with different GFP fluorescence were mixed together without clear borders, or the number of separated regions was higher than approximately five, the arrangement was classified as "mosaic".

In suspension cultures, the homogeneity of GFP expression was evaluated using a fluorescence microscope Olympus Provis AX70 equipped with an FITC (U-MWU) filter set. The images were grabbed with a digital TV camera Sony DXC-950P (Sony Corp., Tokyo, Japan) and processed with Lucia image analysis software (Laboratory Imaging, Prague, Czech Republic). The proportions of cells with high, low, or no GFP fluorescence were estimated by evaluating 100-150 cells. Only lines with clear difference between high and low expression categories are presented in the results section. A suspension was classified as homogenous if the portion of cells with minor classes of GFP expression level did not exceed 5\% in total.

\section{Cloning of transgenic lines}

Four weeks after transformation, the primary calli were transferred onto fresh solid medium containing kanamycin. After the next 3 weeks, the calli were gently resuspended in liquid medium and cultivated on a rotor shaker for a week. Thereafter, the suspension cells were subcultured ( $1.5 \mathrm{ml}$ of suspension into $30 \mathrm{ml}$ of fresh medium) and after additional 7 days when the culture reached stationary growth phase, the cells were used for cloning. The transgenic suspension culture was diluted with MS medium in a ratio $1: 3$ and mixed with $4 \mathrm{ml}$ of similarly prepared wild-type stationary BY-2 culture in a ratio 1:1000. After gentle shaking, $500 \mu \mathrm{l}$ of this mixture was evenly spread onto the Petri dish $(\varnothing 6 \mathrm{~cm})$ with solidified MS medium containing kanamycin. Clones of individual cells appeared as "secondary" calli (approximately 25 per plate) within two weeks.

\section{Molecular analysis}

Total genomic DNA was isolated by Invisorb Spin Plant Mini Kit (Invitek, Berlin, Germany) from 100 mg (fresh weight) of filtered cells. Aliquots of $10 \mu \mathrm{g}$ DNA were cleaved with HindIII and BamHI (Fermentas, Burlington, Canada), which cleave the T-DNA in front and behind the $35 S$ promoter. For methylation analysis the $35 S-G F P$ cassette was cleaved out with HindIII and EcoRI, and thereafter the DNA was subjected to methylation-sensitive 
restriction enzymes that cleave within the 35S-GFP cassette (Bsu15I, Eco72I, Eco47I; Fermentas), and separated on $0.8 \%$ agarose gel. Blotting was performed as described in [38]. Hybridisation with PCR-amplified probe of the whole GFP gene, labelled with DIG-dUTP (Roche Molecular Systems, Inc., Mannheim, Germany), was done according to manufacturer's instructions. Autoradiographic detection was done using chemiluminiscent substrate CDP-Star (Tropix, Bedford, USA). Fidelity of the insertions was confirmed by sequencing a PCR amplified 35S-GFP cassette from total genomic DNA isolated from individual clones of cell line 5/6. PCR was done with Pfu polymerase according manufacturers instruction (Fermentas), sequencing was done by Sequencing laboratory, Faculty of Science, Charles University in Prague, Czech Republic).

\section{Authors' contributions}

EN carried out all the experimental work and participated in manuscript writing. LF conceived the study, coordinated the experimental work and prepared the manuscript. Both authors read and approved the final manuscript.

\section{Acknowledgements}

We are grateful to Dr. SJ Davis and Dr. RD Vierstra (University of Wisconsin-Madison, USA) and to the Arabidopsis Biological Research Center for providing us with the soluble-modified RS-GFP gene, and to Dr. P Ratet (ISVCNRS, France) for providing us with the binary vector $\mathrm{PCP} 60$. Our thanks also belong to Dr. J. Marc for language corrections and Dr. M. Kuthan and Prof. Z. Palkova (Faculty of Science, Charles University in Prague) for letting us analyse GFP fluorescence using a fluorescence stereomicroscope Leica MZI6F in their laboratory. We are also grateful to Prof. Zdenek Opatrny (Faculty of Science, Charles University in Prague) for general support. This work was supported by grants from the Ministry of Education, Youth and Sports of the Czech Republic (LC06004, LC06034 and MSM 0021620858).

\section{References}

I. Nagata T: When I encountered tobacco BY-2 cells! In Tobacco BY-2 Cells. Biotechnology in Agriculture and Forestry Volume 53. Edited by: Nagata T, Hasezawa S, Inzé D. Berlin Heidelberg New York: Springer; 2004:I-5.

2. Harashima $\mathrm{H}$, Shinmyo A, Sekine M: Phosphorylation of threonine $16 \mathrm{I}$ in plant cyclin-dependent kinase $A$ is required for cell division by activation of its associated kinase. Plant J 2007, 52:435-448.

3. Kuthanova A, Fischer L, Nick P, Opatrny Z: Cell cycle phase-specific death response of tobacco $B Y-2$ cell line to cadmium treatment. Plant Cell Environ 2008, 31:1634-1643.

4. Klein TM, Harper EC, Svab Z, Sanford JC, Fromm ME, Maliga P: Stable genetic-transformation of intact Nicotiana cells by the particle bombardment process. Proc Natl Acad Sci U S A 1988, 85:8502-8505.

5. An GH: High-efficiency transformation of cultured tobacco cells. Plant Physiol 1985, 79:568-570.

6. Higaki T, Kutsuna N, Sano T, Hasezawa S: Quantitative analysis of changes in actin microfilament contribution to cell plate development in plant cytokinesis. BMC Plant Biol 2008, 8:80.

7. Joubes J, Inzé D, Geelen D: Improvements of the molecular toolbox for cell cycle studies in tobacco BY-2 cells. In Tobacco BY-2 Cells. Biotechnology in Agriculture and Forestry Volume 53. Edited by: Nagata T, Hasezawa S, Inzé D. Berlin Heidelberg New York: Springer; 2004:7-20.
8. Pröls F, Meyer P: The methylation patterns of chromosomal integration regions influence gene activity of transferred DNA in Petunia hybrida. Plant $J$ 1992, 2:465-475.

9. Iglesias VA, Moscone EA, Papp I, Neuhuber F, Michalowski S, Phelan $\mathrm{T}$, et al: Molecular and cytogenetic analyses of stably and unstably expressed transgene loci in tobacco. Plant Cell 1997, 9:|25|-|264.

10. van Leeuwen W, Ruttink T, Borst-Vrenssen AWM, Plas LHW van der, Krol AR van der: Characterization of position-induced spatial and temporal regulation of transgene promoter activity in plants. J Exp Bot 200I, 52:949-959.

II. Schubert D, Lechtenberg B, Forsbach A, Gils M, Bahadur S, Schmidt R: Silencing in Arabidopsis T-DNA transformants: The predominant role of a gene-specific RNA sensing mechanism versus position effects. Plant Cell 2004, 16:256I-2572.

12. Francis KE, Spiker S: Identification of Arabidopsis thaliana transformants without selection reveals a high occurrence of silenced T-DNA integrations. Plant J 2005, 41 :464-477.

13. Depicker A, Sanders M, Meyer P: Transgene silencing. In Plant Epigenetics Volume 19. Edited by: Meyer P. Blackwell Publishing; 2005:I-3I.

14. Kim SI, Veena , Gelvin SB: Genome-wide analysis of Agrobacterium T-DNA integration sites in the Arabidopsis genome generated under non-selective conditions. Plant J 2007, 5 I:779-79I.

15. Fischer U, Kuhlmann M, Pecinka A, Schmidt R, Mette MF: Local DNA features affect RNA-directed transcriptional gene silencing and DNA methylation. Plant J 2008, 53:I-I0.

16. Müller $\mathrm{E}$, Lorz $\mathrm{H}$, Lutticke $\mathrm{S}$ : Variability of transgene expression in clonal cell lines of wheat. Plant Sci 1996, I I 4:7 I-82.

17. Down RE, Ford L, Bedford SJ, Gatehouse LN, Newell C, Gatehouse JA, et al.: Influence of plant development and environment on transgene expression in potato and consequences for insect resistance. Transgenic Res 200I, 1 0:223-236.

18. Kain SR, Adams M, Kondepudi A, Yang TT, Ward WW, Kitts P: Green fluorescent protein as a reporter of gene-expression and protein localization. Biotechniques 1995, 19:650-655.

19. Ruiz MT, Voinnet O, Baulcombe DC: Initiation and maintenance of virus-induced gene silencing. Plant Cell 1998, 10:937-946.

20. Kalantidis K, Tsagris M, Tabler M: Spontaneous short-range silencing of a GFP transgene in Nicotiana benthamiana is possibly mediated by small quantities of siRNA that do not trigger systemic silencing. Plant J 2006, 45: I006-1016.

21. Mirabella R, Franken C, Krogt GNM van der, Bisseling T, Geurts R: Use of the fluorescent timer DsRED-E5 as reporter to monitor dynamics of gene activity in plants. Plant Physiol 2004, 135:1879-1887.

22. Henderson IR, Jacobsen SE: Epigenetic inheritance in plants. Nature 2007, 447:4I8-424.

23. Lunerova-Bedrichova J, Bleys A, Fojtova M, Khaitova L, Depicker A, Kovarik A: Trans-generation inheritance of methylation patterns in a tobacco transgene following a post-transcriptional silencing event. Plant $J 2008$ in press.

24. Fojtova M, Van Houdt H, Depicker A, Kovarik A: Epigenetic switch from posttranscriptional to transcriptional silencing is correlated with promoter hypermethylation. Plant Physiol 2003, I33:1240-1250

25. Gelvin SB, Kim SI: Effect of chromatin upon Agrobacterium TDNA integration and transgene expression. Biochim Biophys Acta 2007, I769(5-6):410-42I.

26. Neuhuber F, Park YD, Matzke AJM, Matzke MA: Susceptibility of transgene loci to homology-dependent gene silencing. $\mathrm{Mol}$ Gen Genet 1994, 244:230-24I.

27. Brodersen $\mathrm{P}$, Voinnet $\mathrm{O}$ : The diversity of RNA silencing pathways in plants. Trends Genet 2006, 22:268-280.

28. Santi DV, Norment A, Garrett CE: Covalent bond formation between a DNA-cytosine methyltransferase and DNA containing 5-azacytosine. Proc Natl Acad Sci U S A 1984, 81:6993-6997.

29. Koukalova B, Fojtova M, Lim KY, Fulnecek J, Leitch AR, Kovarik A: Dedifferentiation of tobacco cells is associated with ribosomal RNA gene hypomethylation, increased transcription, and chromatin alterations. Plant Physiol 2005, 139:275-286.

30. Muir WH, Hildebrandt AC, Riker AJ: The preparation, isolation, and growth in culture of single cells from higher plants. $\mathrm{Am} J$ Bot 1958, 45:589-597. 
31. Bergmann L: New technique for isolating and cloning cells of higher plants. Nature 1959, 184:648-649.

32. Pischke MS, Huttlin EL, Hegeman AD, Sussman MR: A transcriptome-based characterization of habituation in plant tissue culture. Plant Physiol 2006, I 40: I 255-1278.

33. Nagata T, Nemoto $Y$, Hasezawa S: Tobacco BY-2 cell-line as the Hela-cell in the cell biology of higher-plants. Int Rev Cytol I992, 132: 1-30.

34. Murashige T, Skoog F: A revised medium for rapid growth and bio assays with tobacco tissue cultures. Physiol Plantarum 1962, 15:473.

35. Deblaere R, Bytebier B, Degreve H, Deboeck F, Schell J, Vanmontagu $\mathrm{M}$, et al:: Efficient octopine $\mathrm{Ti}$ plasmid-derived vectors for Agrobacterium-mediated gene-transfer to plants. Nucleic Acids Res 1985, 13:4777-4788.

36. Bolte S, Brown S, Satiat-Jeunemaitre B: The $\mathbf{N}$-myristoylated RabGTPase $\mathbf{m}-\mathbf{R a b}(\mathrm{mc})$ is involved in post-Golgi trafficking events to the lytic vacuole in plant cells. J Cell Sci 2004, I I 7:943-954.

37. Davis S], Vierstra RD: Soluble, highly fluorescent variants of green fluorescent protein (GFP) for use in higher plants. Plant Mol Biol 1998, 36:521-528.

38. Sambrook J, Fritsch EF, Maniatis T: Molecular cloning: a laboratory manual 2 nd edition. Cold Spring Harbor: Cold Spring Harbor Laboratory Press; 1989.

Publish with Bio Med Central and every scientist can read your work free of charge

"BioMed Central will be the most significant development for disseminating the results of biomedical research in our lifetime. "

Sir Paul Nurse, Cancer Research UK

Your research papers will be:

- available free of charge to the entire biomedical community

- peer reviewed and published immediately upon acceptance

- cited in PubMed and archived on PubMed Central

- yours - you keep the copyright

Submit your manuscript here:

http://www.biomedcentral.com/info/publishing_adv.asp 